\title{
Value and impact of international hospital accreditation: a case study from Jordan
}

\author{
Y.A. Halasa, ${ }^{7}$ W. Zeng, ${ }^{1}$ E. Chappy ${ }^{2}$ and D.S. Shepard ${ }^{7}$
}

$$
\begin{aligned}
& \text { قيمة وتأثير الاعتماد الدولي للمستشفيات: دراسة حالة من الأردن }
\end{aligned}
$$

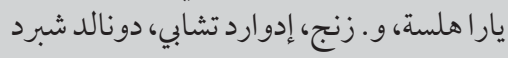

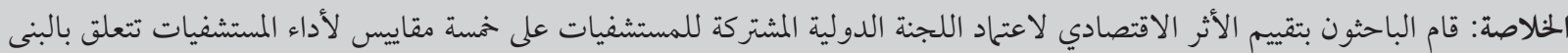

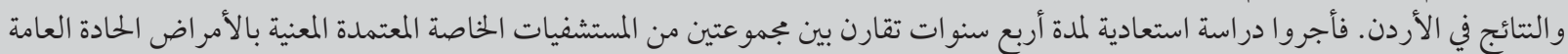

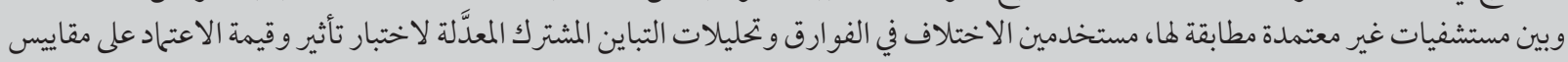

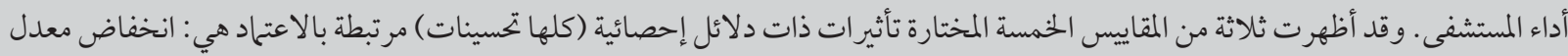

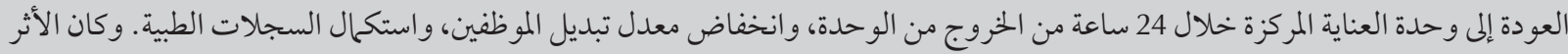

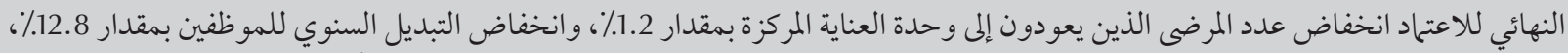

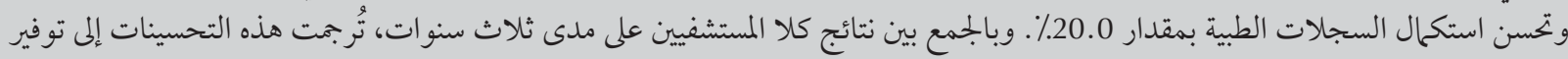
إجمالي قدره 000593 دو لار أمريكي في نظام الرعاية الصحية الأردني.

ABSTRACT We assessed the economic impact of Joint Commission International hospital accreditation on 5 structural and outcome hospital performance measures in Jordan. We conducted a 4-year retrospective study comparing 2 private accredited acute general hospitals with matched non-accredited hospitals, using differencein-differences and adjusted covariance analyses to test the impact and value of accreditation on hospital performance measures. Of the 5 selected measures, 3 showed statistically significant effects (all improvements) associated with accreditation: reduction in return to intensive care unit (ICU) within 24 hours of ICU discharge; reduction in staff turnover; and completeness of medical records. The net impact of accreditation was a 1.2 percentage point reduction in patients who returned to the ICU, $12.8 \%$ reduction in annual staff turnover and $20.0 \%$ improvement in the completeness of medical records. Pooling both hospitals over 3 years, these improvements translated into total savings of US $\$ 593000$ in Jordan's health-care system.

\section{Valeur et impact d'une accréditation internationale des hôpitaux : étude de cas en Jordanie}

RÉSUMÉ Nous avons évalué l'impact économique d'une accréditation internationale des hôpitaux attribuée par une commission conjointe sur cinq mesures de la performance des hôpitaux en termes de structure et de résultats en Jordanie. Nous avons mené une étude rétrospective sur quatre ans, comparant deux hôpitaux généraux de soins aigus privés et accrédités avec des hôpitaux appariés sans accréditation. Nous avons utilisé des analyses de la covariance ajustée et de l'écart des différences pour évaluer l'impact et la valeur d'une accréditation sur les mesures de la performance des hôpitaux. Sur les cinq mesures sélectionnées, trois ont eu des effets positifs statistiquement significatifs associés à l'accréditation : la réduction des retours en service de soins intensifs dans les 24 heures suivant la sortie du patient de ce service ; la réduction de la rotation du personnel ; et l'exhaustivité des dossiers médicaux. L'impact net de l'accréditation était une réduction de 1,2 point de pourcentage du retour des patients en soins intensifs, une baisse de $12,8 \%$ de la rotation annuelle du personnel et une amélioration de 20 \% de l'exhaustivité des dossiers médicaux. Le cumul sur trois ans des améliorations dans ces deux hôpitaux s'est traduit par des économies totales s'élevant à USD 593000 pour le système de soins de santé jordanien.

'The Heller School for Social Policy and Management, Brandeis University, Waltham, Massachusetts, United States of America (Correspondence to D.S.Shepard:shepard@brandeis.edu).

${ }^{2} J o r d a n$ Health Care Accreditation Project, Amman, Jordan.

Received: 05/01/14; accepted: 11/03/14 


\section{Introduction}

Hospital accreditation aims to improve patient safety and strengthen the quality of health care. Quality of care reflects the degree to which health services are consistent with current professional knowledge, meet users' expectations and increase the likelihood of achieving desired health outcomes (1). Improvement in quality is believed to result in fewer mistakes, shorter delays, improvements in productivity, increased market share and lower costs (1). Hospital accreditation-a selfassessment and external quality review mechanism that checks a hospital's conformity with established standards (2) - is perceived as a strategic tool to promote quality and patient safety (3). Joint Commission International (JCI) is the largest international accreditation organization, with 718 accredited or certified organizations and programmes in 63 countries as of December 2014. Hospitals seek accreditation as a voluntary or self-regulated step towards improving their quality of health care, maintaining high standards in healthcare delivery, gaining recognition for excellence and signalling their competitiveness. To achieve these objectives, accreditation aims to change the organizational culture of a health institution and to improve its strategies and tactics towards a continuous improvement in organizational systems and processes (4).

The available literature on the impact of hospital accreditation programmes on hospitals' performance shows mixed results (5). In the United States (US), accredited hospitals have generally shown modest improvements in performance compared with non-accredited hospitals; for example, accredited hospitals provided better emergency response planning $(6,7)$, training $(8)$ and patient safety system initiation and implementation (9), and performed better in care of acute myocardial infarction, heart failure and pneumonia $(6,7,10)$. Other studies, however, have found no such relationships (11-13). The literature on the economics of accreditation consist of studies concerning the explicit costs of seeking accreditation (14) and the design of a planned controlled study (15).

The process of accreditation can be profound $(16,17)$ but daunting (18) for health-care providers and its high cost to hospitals might be a barrier to seeking accreditation (14). Understanding the impact of accreditation on health outputs and outcomes, and the cost savings associated with accreditation, is helpful for policy-makers as well as hospitals facing the decision to commit potentially limited resources to the accreditation process. This paper is the first, to our knowledge, to examine the economic impact of JCI hospital accreditation standards on selected structural and outcome of care measures of hospital performance.

\section{Methods}

\section{Study design}

This study aimed to quantify the impact of implementing JCI standards on 5 selected structural and outcome hospital performance measures, and the monetary value associated with the expected improvement. Our retrospective study compared 2 matched groups of general acute hospitals in Jordan. We used difference-in-differences and adjusted covariance analyses to test the impact of accreditation on the selected hospital performance measures. For each selected measure $\left(Y_{i t}\right)$, treated as a dependent variable, we estimated a random-effect regression model to measure the impact of accreditation on the changes observed in that measure, if any. This difference-in-differences approach, widely used in observational studies over time, controls for possible baseline differences among the hospitals and does not require that the accredited and control hospitals match perfectly (19). This approach assumes that underlying changes in Jordan's health system affect accredited and non-accredited hospitals similarly. The absence of any major initiatives for private hospitals over the study period supports the validity of this assumption.

We used the intervention period, the hospital's accreditation status and the interaction term between these factors as the independent variables. We had 2 observations for each hospital: the first in the pre-intervention period and the second in the intervention period. The model is presented in the equation:

$$
\begin{gathered}
\mathrm{Y}_{\mathrm{it}}=\left(\beta_{0}+\beta_{1} \text { Period }_{\mathrm{t}}+\beta_{2} \text { Accreditation }++\right. \\
\left.\beta_{3} \text { Period }_{\mathrm{t}}\right) \times \text { Accreditation }_{\mathrm{it}}
\end{gathered}
$$

where: Period is a dummy variable equal to 1 if the observations came from the interventions years; $\beta_{1}$ captures aggregate factors that cause changes in the dependent variable(s) during the intervention period; Accreditation is a dummy variable equal to 1 if the observation comes from the accredited hospitals; $\beta_{2}$ captures possible differences between accredited and control hospitals. The coefficient $\beta_{3}$ of the interaction term is the key difference-indifference estimator.

We performed sensitivity analyses to examine the impact of accreditation separately by year. We did this by adding dummy variables (d2007, d2008 and 22009) to the model; these are equal to 1 if the observation came in the corresponding intervention year (2007, 2008 or 2009) and zero otherwise. The pre-intervention year (2006) served as the reference. With this specification, we estimated individual intervention year effects $(\gamma) t$, as shown in the following equation:

$$
\begin{gathered}
\mathrm{Y}_{\mathrm{it}}=\left(\beta_{0}+\beta_{1} \text { Accreditation }+\beta_{2} \text { Period }\right) \\
\times\left(\text { Accreditation }+\gamma_{1} \mathrm{~d} 2007+\gamma_{2} \mathrm{~d} 2008+\right. \\
\left.\gamma_{3} \mathrm{~d} 2009\right)
\end{gathered}
$$




\section{Standards and measures}

We used JCI standards as principles to define 9 related structural and outcome hospital performance measures for potential use (20). Four measures addressed structure of care: rate of completeness of medical records; percentage of repeated X-rays; percentage of scheduled surgeries cancelled; and rate of staff turnover. The other 5 outcome measures were: rate of readmission within 30 days of discharge; rate of return to surgery within 24 hours of the previous surgery; rate of readmission to the intensive care unit (ICU) within 24 hours of discharge from ICU; and proportion of foreign (i.e. non-citizen) patients admitted (a measure of the hospital's international reputation and distinction) (1). We examined these potential measures and found that 5 were feasible to use based on the frequency, reliability, objectivity and availability of data to quantify them: rate of completeness of medical records, rate of staff turnover, rate of readmission within 30 days of discharge, rate of return to surgery within 24 hours, and rate of readmission to ICU within 24 hours of discharge. Table 1 describes the rationale for selecting these measures and their relationship to JCI hospital accreditation standards.

Additionally, we computed a quality improvement index to address the random variation in the rates of events which could be attributed to small numbers and to changing incentives over the years around the period of accreditation. The index converted each available measure to a ratio of its value in each year divided by the value in the pre-accreditation year. We took the inverse of the ratio for return to ICU, return to surgery, readmissions, and staff turnover to make sure all indices corresponded to better achievements. We then computed the geometric mean of those ratios and compared the 2 hospital groups. We estimated a random-effects regression to predict the change in the quality improvement

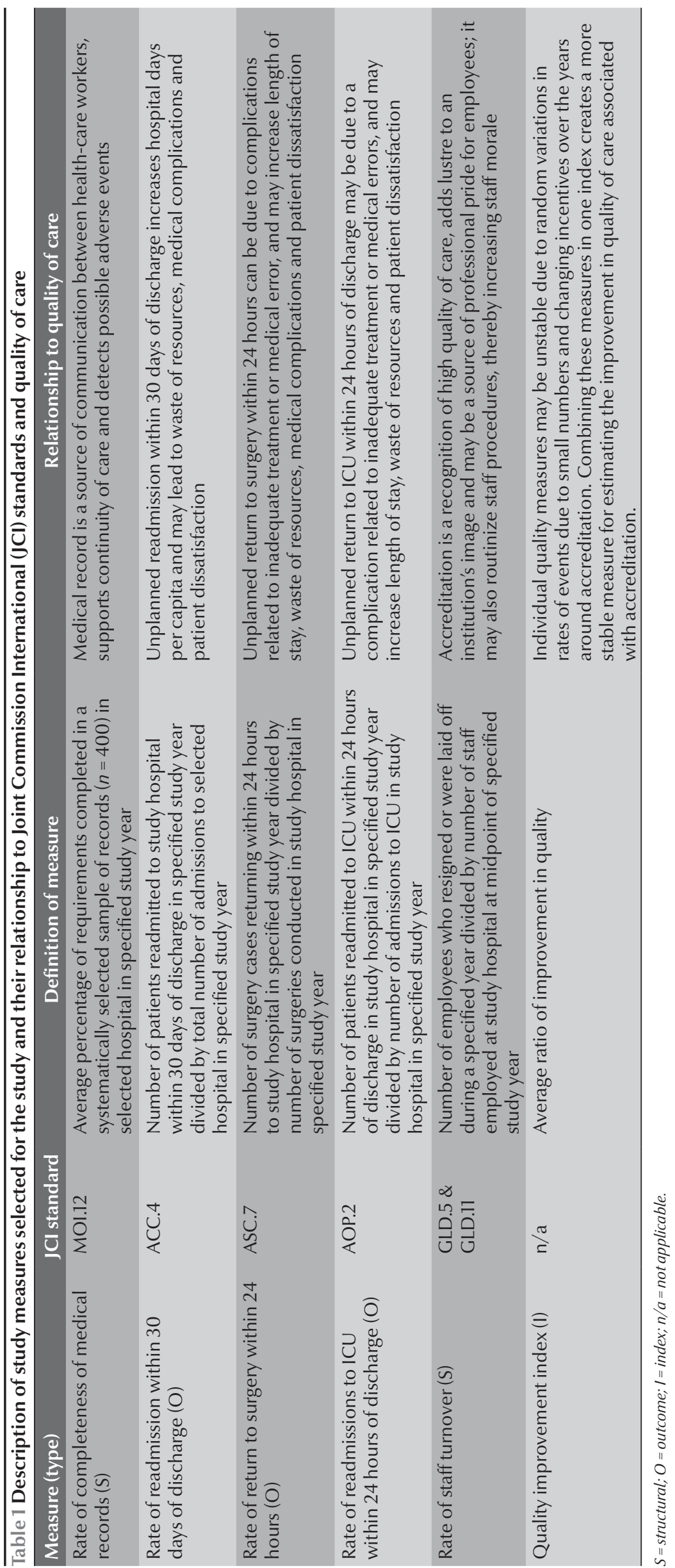


index as a function of year and accreditation status. The 12 observations were for each of the 4 participating hospitals (i) during each of the 3 post-accreditation years $(t)$. The model is shown in the equation:

Quality index (change) $)_{\text {it }}=\beta_{0}+\beta_{1}$ Year $_{t}+$ $\beta_{2}$ Accredited $_{\mathrm{i}}+\alpha_{\mathrm{it}}$

Where the coefficient $\beta_{2}$ estimates the change associated with accreditation status.

\section{Hospital characteristics}

The 2 general acute care hospitals that received JCI accreditation in 2008 participated in this study and were closely matched to control hospitals by type (general acute hospitals); location (the capital, Amman); sector (private, forprofit); and capacity (bed size). Of the 4 eligible control hospitals, 2 agreed to participate. The average bed sizes were 133 for the 2 accredited hospitals and 115 for the 2 control hospitals. The average bed size of the control hospitals was close to the average bed size (109 beds) of 2 other non-accredited hospitals that declined to participate.

\section{Study period}

Health providers have been shown to perceive improvements in quality of care during and after the accreditation process $(16,17)$. Therefore, we hypothesized that each hospital's preparation for and participation in the process of accreditation led to enhanced and accelerated adherence to quality standards compared with what would have occurred otherwise. Therefore, we based our study design on a 4-year period from 2006 to 2009 . The pre-intervention period was the first year in our study period (2006). The intervention period (2007-09) is based on the assumption that quality of care improves during the year preparing for accreditation $(16,17)$, with the improvements continuing through and after accreditation. Thus, the intervention period spans 3 years: the year preparing for accreditation, the year of accreditation, and the year following accreditation.

\section{Cost}

To estimate cost savings associated with improvements in the selected hospitals' outcome performance measures, we first approximated the cost of the medical services. The cost of a normal delivery, which is a frequent and brief $(2-3$ days) reason for hospitalization, was used to estimate the cost of a recurrent admission. An ICU admission for a respiratory infection was used to estimate the cost of return to ICU. A general surgery admission represented the cost of return to surgery. We obtained the cost of these proxy services by randomly choosing 240 admissions (20 instances of each of 3 services in 4 hospitals).

To estimate the cost savings from a possible reduction in staff turnover, we obtained the average salary of employees at each of the participating hospitals. Based on common practice, we estimated that on average, the hospital would save 3 months of salary (the customary probationary period and estimated time needed for new staff orientation). Since hospital charges were obtained in 2008, we adjusted these costs to the year 2013 using the projected consumer price inflation index for Jordan.

\section{Ethical considerations}

Hospitals agreed to participate after an in-depth discussion of the importance and methodology of this study and the expected impact of its results. Each hospital's general director signed the consent form. Due to the retrospective nature of this study, it was not possible to obtain patients' consent to review their medical records. However, during the sample selection process the medical department in each hospital concealed patients' identities before they provided the needed data to study investigators. The Brandeis Committee for Protection of Human Subjects in
Research reviewed and approved the research protocol (IRB number: 11056).

\section{Results}

\section{Baseline data}

Comparing measures in the pre-intervention year for all participating hospitals showed that, on average, the rate of staff turnover was higher for the to-beaccredited hospitals (36.1\%) compared with the control hospitals (24.7\%). Similarly, at baseline, to-be-accredited hospitals performed better compared with control hospitals in the rate of readmission within 30 days of discharge ( $5.1 \%$ versus $7.2 \%$ respectively); rate of return to surgery within 24 hours $(0.2 \%$ versus $0.6 \%$ respectively) and completeness of medical records (62.0\% versus $53.0 \%$ respectively). Control hospitals performed better, however, compared with to-be-accredited hospitals in the rate of readmission to ICU within 24 hours of discharge from ICU ( $1.3 \%$ versus $1.4 \%$ respectively). However, none of these baseline differences was statistically significant and the mixed pattern suggests no large differences between the control and intervention hospitals.

\section{Impact of accreditation}

Of the 5 measures, 3 showed statistically significant changes due to accreditation: the rate of return to ICU within 24 hours; the rate of completeness of medical records; and the rate of staff turnover. As presented in Table 2, all of these 3 measures favoured the intervention group.

Figure 1 displays the rate of return to ICU within 24 hours for both accredited and control hospitals. The absolute changes in these rates were $-0.37 \%$ in the JCI accredited hospitals (from an average rate of $1.44 \%$ in 2006 to an average rate of $1.06 \%$ over the 3 intervention years 2007-09) compared with $+0.82 \%$ in the control hospitals (from 1.33\% to $2.15 \%$ ). 


\begin{tabular}{|c|c|c|c|c|c|}
\hline Variable & $\begin{array}{l}\text { Accredited } \\
\text { hospitals }^{\mathrm{a}} \\
(\%)\end{array}$ & $\begin{array}{c}\text { Control } \\
\text { hospitals (trend) } \\
(\%)\end{array}$ & $\begin{array}{l}\text { Net impact of } \\
\text { accreditation }^{b} \\
(\%)\end{array}$ & $P$-value & $\begin{array}{c}\text { Monetary } \\
\text { savings per } \\
\text { hospital per } \\
\text { year in } 2013 \\
\quad(\text { US\$) }\end{array}$ \\
\hline $\begin{array}{l}\text { Readmission to hospital within } 30 \\
\text { days }\end{array}$ & 0.56 & 0.43 & 0.13 & 0.857 & - \\
\hline Return to ICU within 24 hours & -0.37 & 0.82 & -1.20 & $<0.001$ & 56595 \\
\hline Return to surgery within 24 hours & -0.07 & -0.21 & 0.14 & 0.731 & - \\
\hline Staff turnover per year & -4.97 & 7.83 & -12.8 & 0.005 & 42290 \\
\hline Completeness of medical records & 19.8 & -0.2 & 20.0 & 0.002 & - \\
\hline All indicators & - & - & - & - & 98885 \\
\hline
\end{tabular}

${ }^{a}$ Changes from pre-intervention year (2006) compared with average of 3 intervention years (2007-09). ${ }^{b}$ Net impact is the differences in differences associated with the accreditation status.

'Savings were calculated only for indicators for which results could be valued in monetary terms and the difference between accredited and control hospitals was statistically significant. Results converted at July 2013 exchange rate of US $\$ 1=0.707$ Jordanian dinars.

$I C U=$ intensive care unit.

The difference between these changes yielded a $1.20 \%$ net impact due to JCI accreditation $(P<0.001)$. The monetary saving per hospital per year was US\$ 56595 .

Figure 2 shows the rates of staff turnover for both accredited and control hospitals. The absolute changes in these rates were $-5.0 \%$ in the JCI accredited hospitals (from an average rate of $36.1 \%$ in 2006 to an average rate of $31.2 \%$ over the 3 intervention years 2007-09) compared with $+7.8 \%$ in the control hospitals (from $24.7 \%$ to $32.6 \%$ ). The difference gives a $12.8 \%$ net impact due to JCI accreditation $(P=0.005)$. The monetary saving per hospital per year was US\$ 42290.

Figure 3 shows the rates of completeness of medical records for both accredited and control hospitals. The absolute changes in these rates were $+19.8 \%$ in the JCI accredited hospitals (from an average rate of $62.0 \%$ in

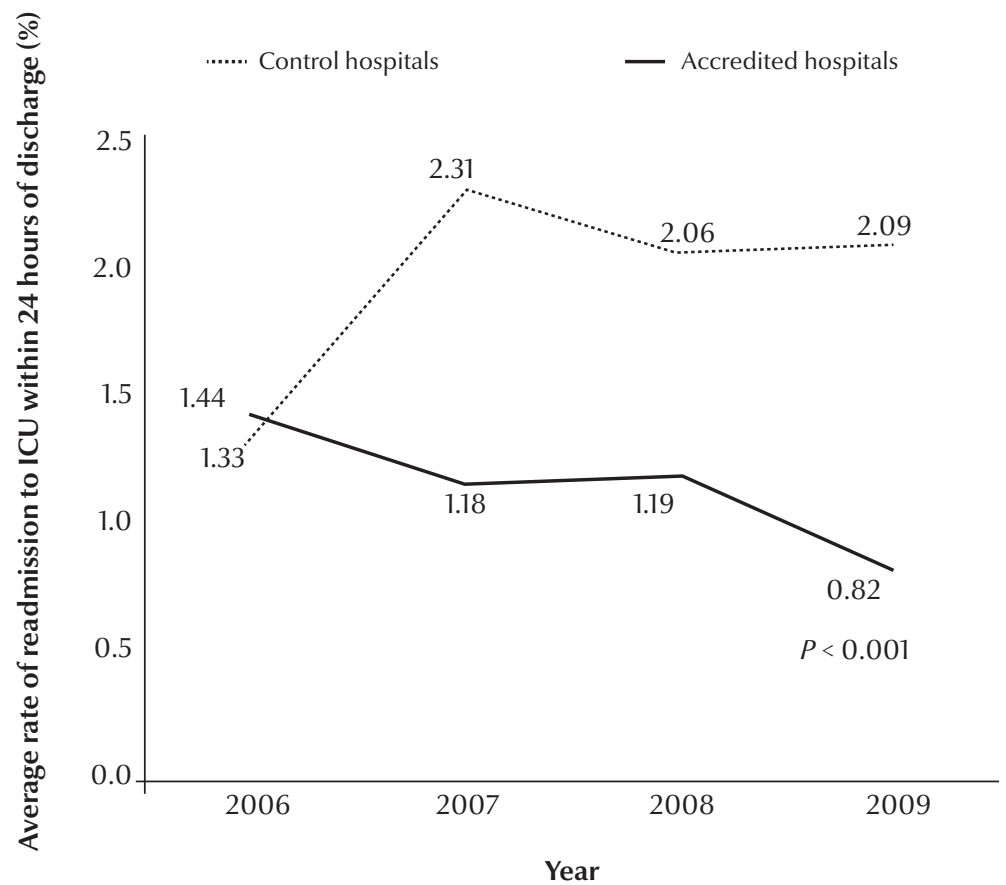

Figure 1 Average rate of return to the intensive care unit (ICU) within 24 hours of discharge for accredited and control hospitals by year, 2006-2009 
2006 to an average rate of $81.8 \%$ over the 3 intervention years 2007-2009) compared with $-0.19 \%$ in the control hospitals (from $53.0 \%$ to $52.8 \%$ ). The difference gave a $20.0 \%$ net impact due to JCI accreditation $(P=0.002)$. As this item is a structural measure rather than an outcome, we could not attribute any monetary savings to it.

Two measures were not statistically significant: the rate of readmission to hospital within 30 days $(P=0.857)$, and the rate of return to surgery within 24 hours $(P=0.731)$.

The total saving from combining the 2 measures (reduction in return to ICU within 24 hours of discharge and reduction in staff turnover) was US\$ 98885 per accredited hospital per year. This amount aggregates to US\$ 296655 per hospital over the 3-year period, with an aggregate saving of US\$ 593310 for the health system in Jordan for the 2 accredited hospitals.

Figure 4showsthequalityimprovement index for accredited and control hospitals in the intervention period compared with the pre-intervention period. A quality index of 0 indicates no difference in the index relative to the base year 2006, while a positive number represents improved quality. For example, the average value of $37.5 \%$ for accredited hospitals in the year 2007 indicates an improvement of nearly $38 \%$ in the quality index compared with the baseline year (2006). Accreditation status was associated with a $119.3 \%$ improvement in the quality index compared with the baseline year $2006(P<0.001)$. With a root mean square deviation of $29.5 \%$, the improvement in quality corresponded to a large effect size of 1.74.

\section{Sensitivity analyses}

Sensitivity analyses using the post-intervention year effect showed a $20.0 \%$ net impact on the completeness of medical records $(P=0.027)$ and $-13.0 \%$ net impact on staff turnover $(P=0.027)$, illustrating a favourable impact due to JCI accreditation. However, the impact on the 3 other measures were not statistically significant: return to ICU within
24 hours of discharge (impact $=-1.0 \%$, $P=0.19$ ), return to surgery (impact $=$ $0.0 \%, P=1.00)$ or readmission within 30 days of discharge (impact $=0.2 \%, P$ $=0.87$ ).

\section{Discussion}

Donabedian conceptualized quality of care as a combination of structure, process and outcomes, whereby good structure increases the likelihood of good process and good process increases the likelihood of good outcome (21). Structural factors describe the environment and staff characteristics. Process describes the contents or course of services and outcomes examine the results of service. Our findings are consistent with Donabedian's theory. The quality improvement index showed that, in general, being accredited showed a consistent improvement in the structural and outcome measures in the intervention period compared with the pre-intervention period. This result supports our hypothesis that

....... Control hospitals _ - Accredited hospitals

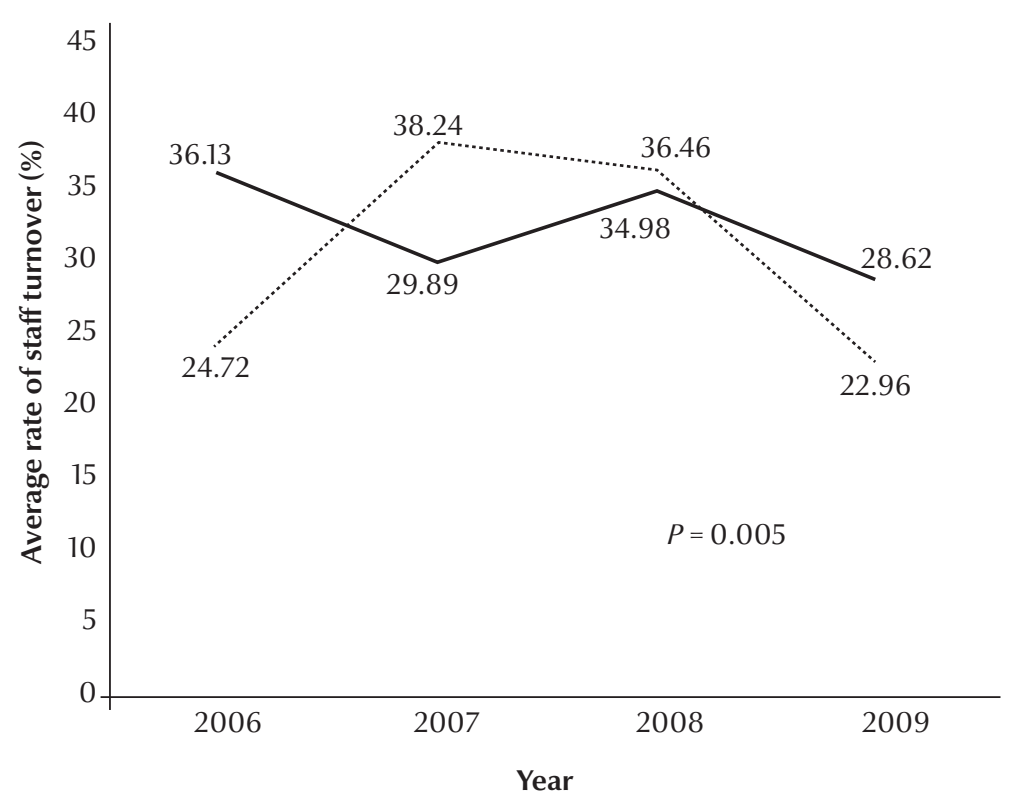

Figure 2 Average rate of staff turnover for accredited and control hospitals by year, 2006-2009 


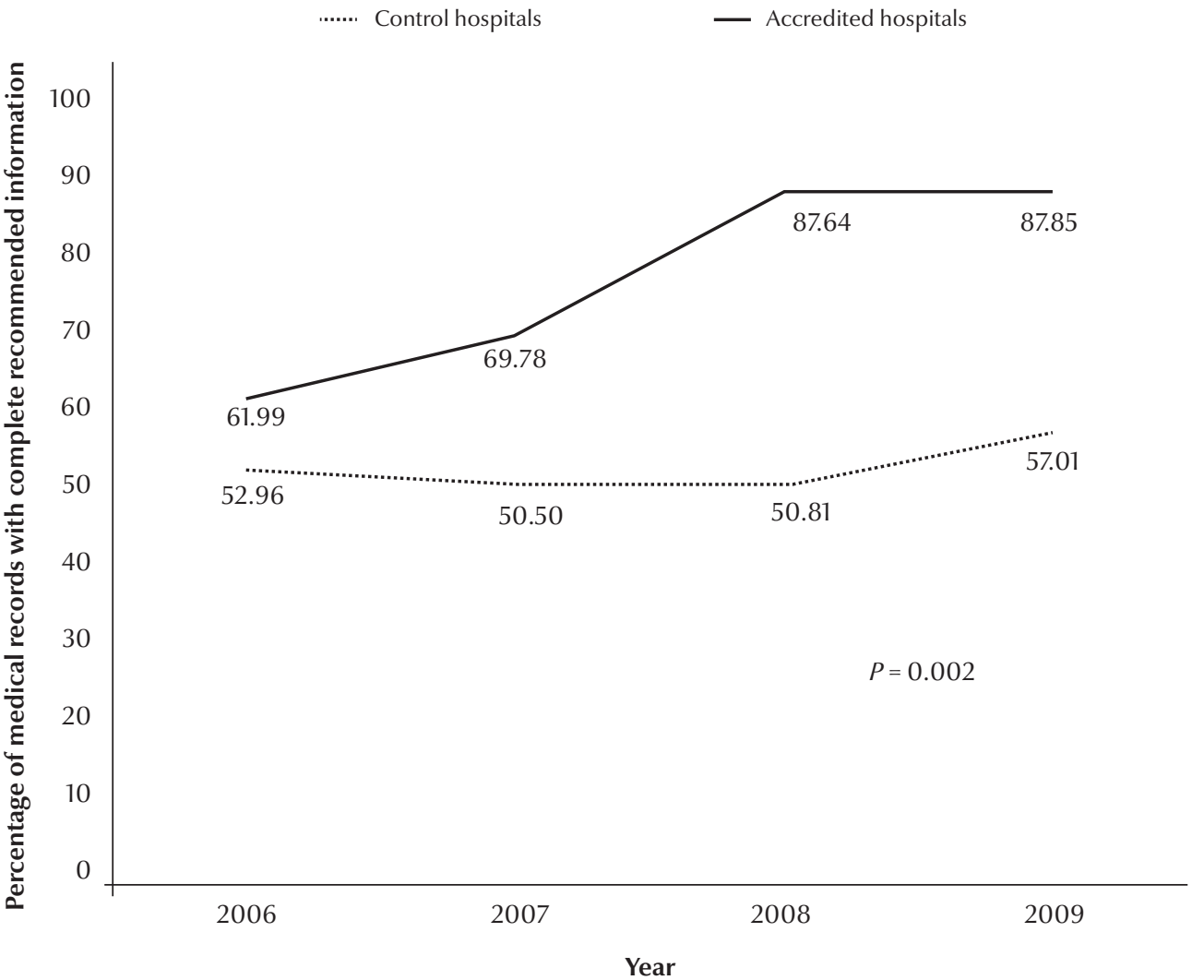

Figure 3 Average rate of completeness of medical records for accredited and control hospitals by year, 2006-2009

preparation for and participation in the process of accreditation enhances and accelerates adherence to quality standards.

Because this study had a small number of hospitals, we computed the average rate of the measures by hospital group in the intervention years and compared these averages with the rates in the pre-intervention year. Our results show that engagement in the accreditation process is positively associated with reductions in the rate of patients readmitted to ICU within 24 hours of discharge from ICU and in the rate of staff turnover. The results of the core analyses and the sensitivity analyses for completeness of medical records and staff turnover support our hypothesis of a positive association between organizational structure and process. The results demonstrate that accredited hospitals achieved substantial improvement in the completeness of medical records compared with the control hospitals. Both control and accredited hospitals started with a moderate level of completeness. However, over the intervention years the level of completeness of medical records in the accredited hospitals improved noticeably (81.8\%) compared with the non-accredited hospitals (52.8\%).

The results of the sensitivity analyses agreed with the results of our core analyses in terms of similar estimated impacts. The classification between significant or not significant impacts of accreditation did not change for 4 outcomes, but did change for one. The outcome for which significance changed (return to ICU within 24 hours of discharge) likely resulted from substantial random variation for individual years in this relatively rare event compared with more stable findings when years were pooled. The 2 lowest individual years had 0 and $3 \mathrm{pa}-$ tients returning to ICU in one hospital, whereas when years were pooled, the 2 lowest observations were 31 and 33 patients. For this rare event, the attempt to examine individual years introduced too much random variation to obtain statistical significance. Our core analysis avoided this artefact.

Our results suggest that the hospitals' engagement in the accreditation process was associated with higher improvement in their quality of care (Figure 4). We noted that after obtaining accreditation, these hospitals possibly relaxed their monitoring and implementation of JCI indicators. However, the slight reduction in the relative quality index $(0.75 \%$ per year compared with the base year of 2006) was not statistically significant $(P=0.74)$.

The evolution of accreditation standards over time might create difficulties in evaluating their impact. We believe our study design successfully addressed this challenge. First, most of 


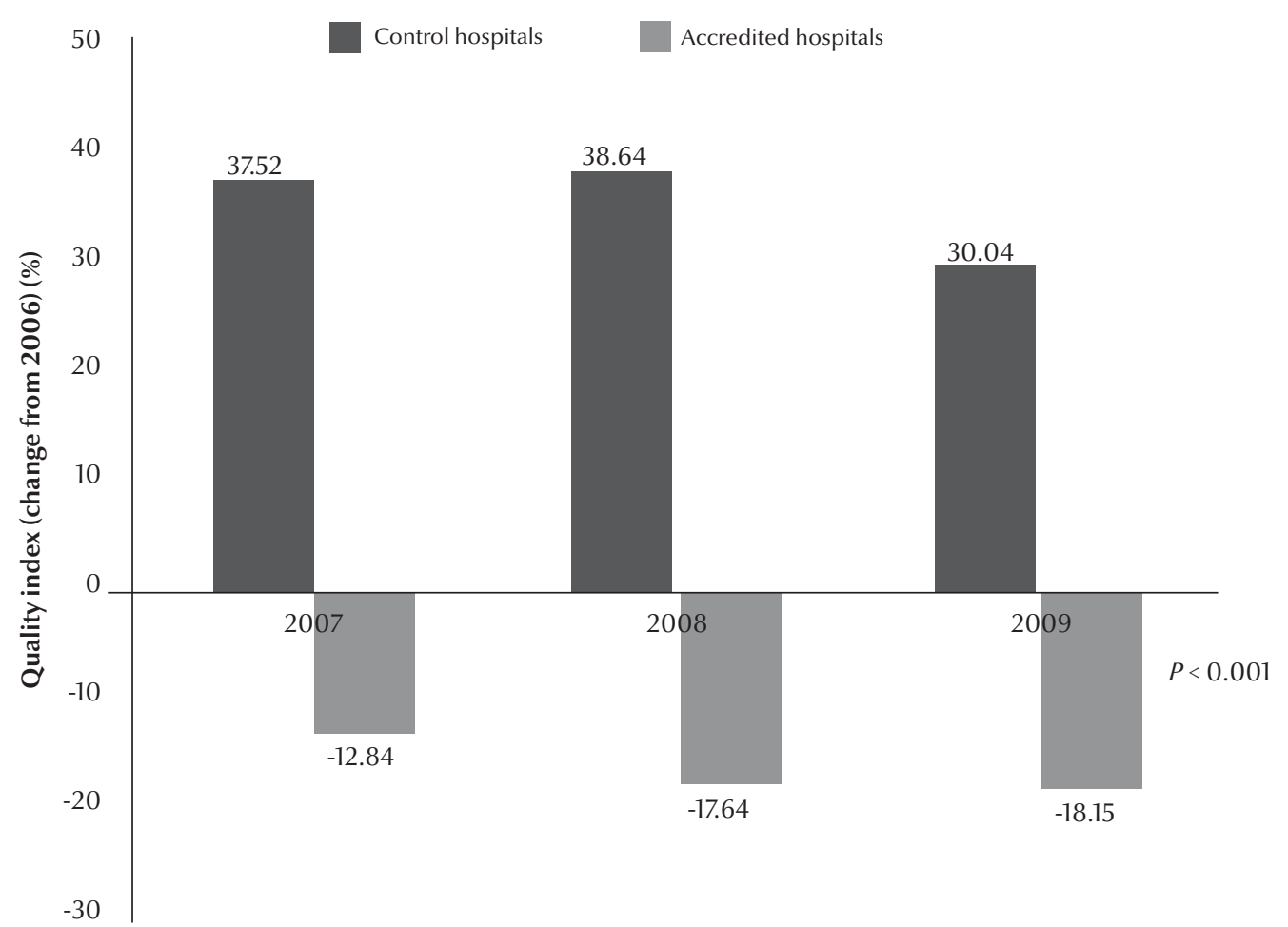

Figure 4 Quality improvement index for accredited and control hospitals by year, 2007-2009

our measures were outcome measures, so even if the specifications of JCI indicators changed over time, the overall impact of JCI accreditation would still be measurable and give a clear picture of a hospital's performance. Secondly, we used longitudinal comparisons and tracked results over 4 years, including pre- and post-intervention periods in both accredited and control hospitals. Thirdly, the selected measures were available retrospectively in both accredited and control hospitals for the duration of the study period; we were therefore able to use the difference-indifferences analysis to control for external factors that might have influenced hospitals' performance measures.

Of the US\$ 98885 average savings per accredited hospital per year, 57\% was from preventing adverse events that led to returning to the ICU within 24 hours of discharge, thus benefitting governments, health insurers and households. Savings from lower staff turnover (43\% of total savings per year) benefits hospitals through reductions in their operating budget. The hospitals' operating costs were not available for the study period. Assuming hospitals in Jordan are following international patterns (22), we project that a hospital's annual operating budget averages US\$ 4 million, so the annual savings were about $2 \%$ of the annual operating budget. Although we were unable to ascertain the actual cost of an accreditation, a US study found it represented about $1 \%$ of a hospital's annual budget (23). If this result were applied in Jordan, it suggests that accreditation would pay off financially in just 6 months, or a return of $200 \%$ per year.

Our study had several limitations. First, the sampling method may have resulted in a selection bias among control hospitals; of the 4 control hospitals matched to the accredited hospitals, only 2 agreed to participate. However, the characteristics of these 2 non-participating hospitals were similar to those of the 2 control hospitals that agreed to participate in this study. Secondly, our sample, although covering all accredited acute general hospitals in Jordan during the study period, was relatively small and therefore may be subject to sample variation. Thirdly, the primary reasons for recording information in patients' medical records are to support the delivery of good care, clinical decision-making and communication between health-care workers, and to ensure continuity of care. A medical record is also a resource for detecting adverse events, which, if addressed, can improve the quality of care in the hospital. The cost of these adverse events was estimated at 6.5 times the cost of an admission with no adverse events (24). Unfortunately, we were able to assess only the completeness of the medical records, not the improvement in the content of patient clinical records. Therefore, we were not able to estimate any cost saving associated with improvement in this measure. Fourthly, we were not able to adjust for risk factors due to lack of an algorithm to do the adjustment specifically for Jordan, and the unavailability of the 
historical diagnostic or comorbidity data needed to perform the risk adjustment. However, using the differencein-differences approach means that each hospital served as its own control. Furthermore, no major changes occurred in the health system in Jordan during the study period, as evidenced by only minor changes in key trends in hospital statistics. For example, from 2006 through 2009, bed capacity per capita fell by $1.2 \%$ per year, while admissions per capita rose by $1.8 \%$ per year (25). These national statistics give us the confidence that no major changes occurred during the study period that would make risk adjustment a necessity. Finally, it should be noted that the study was limited in scope by the available data and it therefore covered only a few hospital performance measures.

With increasing interest in healthcare accreditation, this study's methodology and results are useful for researchers who might wish to replicate the study in other types of healthcare facilities and in other countries.
In conclusion, our results showed that accredited hospitals improved 2 structural and 1 outcome measures compared with the control hospitals. These measures fall under the direct supervision of hospital management. The 2 outcome measures that did not improve (return to surgery and readmission within 30 days of discharge) are primarily under the control of individual physicians, who are independent practitioners who may admit patients to multiple hospitals, both accredited and unaccredited. Their indirect relationship to the hospital and possible crossover substantially reduces the possibility that accreditation would impact these measures. Finally, the quality improvement index, a composite of all 5 indicators, showed a significantly greater improvement in the performance of accredited hospitals compared with the control hospitals. These significant improvements in 3 measures were associated with direct cost savings that would benefit both hospitals and the overall health-care system.

\section{Acknowledgements}

For their assistance in collecting, analysing and interpreting data, the authors are indebted to: Abdalla $\mathrm{Al}$ Bashier, Fawzi Al Hamouri, Nael Al Masalha, Walid Al Khalidi, Bassem Saeed, Sameer Qassim, Tareq Mansour, Mohamad Salah Al Said, Rana Al Qaisi, Fatina Al Zuraiqi, Sofi Al Ramini, Randa Al Khaldi, Mohammad Asfour, Dalal Darabseh, Fawzi Hulliel, Khawla Safi, Amal Al-Fayoomi, Mahmood Yaseen, Sahar Al Masri, Abdulla AlZamel, Tamara Qeytoqa, Samer Bin Ali, Shereen Abu Manneh, Farid Massarweh, Sawsan Haddadin, Tamer Abo Ruman, Amjad Biedas, Ola Abo Kwaik, Mahmmoud Tahat, Amer Ramaha, Amer Kutafan, and Helda Halasa. We also thank Bushra Al-Ayed from the Jordan Health Care Accreditation Council for assistance with study coordination, training and monitoring, and Clare L. Hurley from Brandeis University for editorial assistance.

Funding: Joint Commission International to Brandeis University.

Competing interests: None declared.

\section{References}

1. Buttell P, Hendler R, Daley J. Quality in healthcare: concepts and practice. In: Cohn K, Hough D, editors. The business of healthcare. Westport (CT): Praeger; 2008.

2. Hamm MS. The fundamentals of accreditation. Washington (DC): American Society of Association Executives; 1997.

3. Dror $Y$. Promoting quality and patient safety via the new integrated hospital accreditation programme. World Hosp Health Serv. 2010;46(1):41-3. PMID:20614684

4. Chiu A, Seto WH, Lai L. Journey of a Hong Kong public teaching hospital in preparation of hospital accreditation. Hong Kong Med J. 2011 Jun;17(3):231-6. PMID:21636871

5. Greenfield D, Braithwaite J. Health sector accreditation research: a systematic review. Int J Qual Health Care. 2008 Jun;20(3):172-83. PMID:18339666

6. Niska RW, Burt CW. Emergency response planning in hospitals, United States: 2003-2004. Adv Data. 2007 Aug 20;(391):1-13. PMID:17874715

7. Schmaltz SP, Williams SC, Chassin MR, Loeb JM, Wachter RM Hospital performance trends on national quality measures and the association with Joint Commission accreditation. J Hosp Med. 2011 Oct;6(8):454-61. PMID:21990175

8. Niska RW, Burt CW. Training for terrorism-related conditions in hospitals: United States, 2003-04. Adv Data. 2006 Dec 11;(380):1-8. PMID:17217184
9. Longo DR, Hewett JE, Ge B, Schubert S. Hospital patient safety: characteristics of best-performing hospitals. J Healthc Manag. 2007 May-Jun;52(3):188-204. PMID:17552355

10. Landon BE, Normand SL, Lessler A, O'Malley AJ, Schmaltz S, Loeb JM, et al. Quality of care for the treatment of acute medical conditions in US hospitals. Arch Intern Med. 2006 Dec 11-25;166(22):2511-7. PMID:17159018

11. Hosford SB. Hospital progress in reducing error: the impact of external interventions. Hosp Top. 2008 Winter;86(1):9-19. PMID:18362089

12. Sack C, Lütkes P, Günther W, Erbel R, Jöckel KH, Holtmann GJ. Challenging the holy grail of hospital accreditation: a cross sectional study of inpatient satisfaction in the field of cardiology. BMC Health Serv Res. 2010;10:120. PMID:20459873

13. Sack C, Scherag A, Lütkes P, Günther W, Jöckel KH, Holtmann $\mathrm{G}$. Is there an association between hospital accreditation and patient satisfaction with hospital care? A survey of 37,000 patients treated by 73 hospitals. Int J Qual Health Care. 2011 Jun;23(3):278-83. PMID:21515636

14. Zarkin GA, Dunlap LJ, Homsi G. The costs of pursuing accreditation for methadone treatment sites: results from a national study. Eval Rev. 2006 Apr;30(2):119-38. PMID:16492995

15. Mumford V, Greenfield D, Hinchcliff R, Moldovan M, Forde K, Westbrook JI, et al. Economic evaluation of Australian acute care accreditation (ACCREDIT-CBA (Acute)): study protocol 
for a mixed-method research project. BMJ Open. 2013;3(2):3. PMID:23396564

16. El-Jardali F, Jamal D, Dimassi H, Ammar W, Tchaghchaghian V. The impact of hospital accreditation on quality of care: perception of Lebanese nurses. Int J Qual Health Care. 2008 Oct;20(5):363-71. PMID:18596050

17. Yildiz A, Kaya S. Perceptions of nurses on the impact of accreditation on quality of care: a survey in a hospital in Turkey. Clinical Governance: An International Journal. 2014;19:6982.

18. Manzo BF, Brito MJ, Corrêa Ados R. Implicacoes do processo de Acreditacao Hospitalar no cotidiano de profissionais de saude. [Implications of hospital accreditation on the everyday lives of healthcare professionals]. Rev Esc Enferm USP. 2012 Apr;46(2):388-94. PMID:22576543

19. Wooldridge JM. Introductory econometrics: a modern approach. 5th ed. Mason $(\mathrm{OH})$ : South-Western Cengage Learning; 2013.
20. Joint Commission International accreditation standards for hospitals. 5th ed. Oak Brook (IL): Joint Commission International; 2014.

21. Donabedian A. The quality of care. How can it be assessed? JAMA. 1988 Sep 23-30;260(12):1743-8. PMID:3045356

22. Shepard D, Hodgkin D, Anthony Y. Analysis of hospital costs: a manual for managers. Geneva: World Health Organization; 2000.

23. Rockwell DA, Pelletier LR, Donnelly W. The cost of accreditation: one hospital's experience. Hosp Community Psychiatry. 1993 Feb;44(2):151-5. PMID:8432499

24. Ehsani JP, Jackson T, Duckett SJ. The incidence and cost of adverse events in Victorian hospitals 2003-04. Med J Aust. 2006 Jun 5;184(11):551-5. PMID:16768660

25. The Hashemite Kingdom of Jordan Department of Statistics [Internet]. Amman: Department of Statistics; 2003-2010 (http:// www.dos.gov.jo/sdb/dos_home/dos_home_e/main/index. htm, accessed 15 December 2014). 